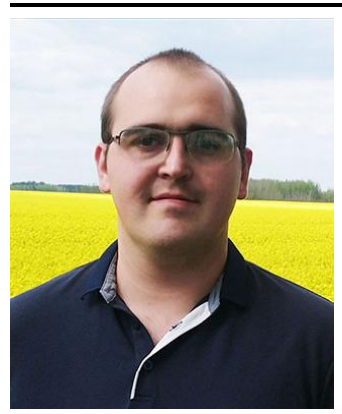

УДК 631.171/.173

https://doi.org/10.47612/978-985-7149-55-1-2020-189-194

Александр Русакович, магистр экономических наук, научный сотрудник

Институт системных исследований в АПК НАН Беларуси, г. Минск

\section{К вопросу развития материально-технической базы сельского хозяйства}

Постоянно изменяющиеся факторы внешней и внутренней среды нацеливают аграрных товаропроизводителей на непрерывное обновление материально-технической базы, предполагающее внедрение современных достижений науки и техники. Специфика аграрного производства предопределяет внутренние факторы, а меры государственного регулирования аграрной сферы внешние. Все это требует от аграрных товаропроизводителей активизации инвестиционной деятельности, при осуществлении которой важным является определение приоритетных направлений вложения ресурсов.

Развитие материально-технической базы сельского хозяйства осуществляется в результате двух взаимодополняющих параллельных процессов: воспроизводства основных и оборотных средств. Под первым необходимо понимать непрерывное обновление основных средств пугем приобретения, строительства, реконструкции, технического перевооружения, модернизации и капитального ремонта. Процесс воспроизводства оборотных средств связан с их обращением на стадиях кругооборота.

Неоднородность материально-технических ресурсов, специфика воспроизводства каждого из них требует соблюдения определенных принципов при их формировании и развитии (рис. 1). Приведенные принципы предусматривают, что для получения большей отдачи от ресурсов необходимо обеспечить их полный набор, а также стремиться к оптимальному их соотношению, нормы расхода должны быть прогрессивными, следует активнее внедрять инновации. В связи с этим для повышения эффективности развития материальнотехнической базы сельского хозяйства нами были предложены: методические подходы к оценке и определению приоритетов формирования и развития материально-технической базы сельскохозяйственных организаций, организационно-экономическая модель ее формирования и развития на инновационной основе, а также направления совершенствования процесса ее формирования и развития.

Методические подходы к оценке и определению приоритетов формирования материально-технической базы сельскохозяйственных организаций включают алгоритм определения приоритетных направлений инвестирования материально-технической базы и методику оценки инвестиционно-инновационного потенциала сельскохозяйственных организаций.

Разработанный алгоритм, который позволяет выявлять как приоритеты инвестирования материально-технической базы, так и резервы роста эффективности аграрного производства по направлениям производственной специализации, включает четыре этапа (рис. 2).

Методика оценки инвестиционно-инновационного потенциала сельскохозяйственных организаций состоит из четырех этапов: выбор и расчет частных показателей; их нормирование; расчет частных интегральных показателей; расчет обобщающего интегрального показателя. Система показателей включает четыре блока: 1) оценка ресурсного потенциала (балл плодородия сельскохозяйственных угодий, фондообеспеченность, физический износ основных средств, обеспеченность трудовыми ресурсами, стоимость оборотных средств в расчете на 100 га сельскохозяйственных угодий); 2) оценка использования инноваций (доля посевов элитными семенами, доля использованных племенных животных, доля использования удобрений, средств защиты растений и животных, кормов, произведенных по инновационным технологиям); 3 ) оценка экономической эффективности деятельности (урожайность зерновых и зернобобовых; среднегодовая продуктивность коров; производительность труда; показатели рентабельности реализованной продукции, активов, персонала, инновационной продукции;

Системность-
$\begin{gathered}\text { Постоянное обеспечение производства } \\ \text { всеми видами ресурсов }\end{gathered}$

Рис. 1. Основные принципы развития материально-технической базы сельского хозяйства Примечание. Рисунок составлен автором по результатам собственных исследований. 
Этап 1. Отбор факторов регрессионной модели एᄂ

Этап 2. Построение регрессионных моделей

Этап 3. Определение приоритетных направлений инвестирования материально-технической базы

Этап 4. Выявление резервов роста показателей экономической эффективности сельскохозяйственных

организаций за счет более полного использования материально-технических и трудовых ресурсов

Рис. 2. Алгоритм определения приоритетных направлений инвестирования материально-технической базы Примечание. Рисунок составлен автором на основании собственных исследований.

фондоотдача); 4) оценка финансового состояния (коэффициенты текущей ликвидности, обеспеченности собственными оборотными средствами, обеспеченности обязательств активами). Отсутствие блока, характеризующего инвестиционный потенциал организации, обусловлено тем, что в иных блоках представлены показатели, опосредованно характеризующие инвестиционную деятельность (показатели износа и движения основных средств) и возможности ее осуществления (финансовое состояние).

Разработанная методика позволяет достоверно оценить инвестиционно-инновационный потенциал организаций, проводить сравнения между ними, составлять рейтинг, а также прослеживать динамику изменения инвестиционно-инновационного потенциала аграрных товаропроизводителей, изучать особенности развития конкретных организаций, разрабатывать предложения по дальнейшему их развитию на основании полученных данных.

Развитие материально-технической базы сельского хозяйство должно основываться на внедрении инновационных технологий в производственный процесс. В результате проведенных исследований было установлено, что одним из факторов, сдерживающих инновационное развитие в аграрной отрасли, является отсутствие развитого промежуточного звена (инновационной инфраструктуры) между наукой и производством. Поэтому нами разработана организационно-экономическая модель формирования и развития материальнотехнической базы сельского хозяйства на инновационной основе, предполагающая создание и развитие агротехнопарков и информационно-консультационной службы сельского хозяйства.

Учитывая особенности отечественного агропромышленного комплекса, считаем, что агротехнопарки следует основывать в форме партнерств (ассоциаций, объединений), в состав которых входят аграрные учебные заведения, научные организации, сельскохозяйственные, агросервисные, перерабатывающие и прочие заинтересованные организации.

Агротехнопарки предлагается создавать по продуктовому признаку, то есть их деятельность должна быть направлена на инновационное развитие аграрного производства и переработки определенного вида продукции. Так, нами видится возможность создания отдельных агротехнопарков, занимающихся внедрением инноваций в области производства и переработки зерна, картофеля, рапса, льна, сахарной свеклы, овощей, плодов, свинины, продукции скотоводства и птицеводства. Следует подчеркнуть, что учреждения образования, научные организации и аграрные товаропроизводители могут одновременно являться членами нескольких агротехнопарков. Вхождение в агротехнопарк организаций, производящих и перерабатывающих сельскохозяйственную продукцию, обеспечит более высокую рентабельность производства благодаря сохранению добавочной стоимости внутри агротехнопарка.

Агротехнопарк можно представить как совокупность пяти звеньев: управленческого, производственного, образовательного, научного, маркетингового. Предлагаемая модель их взаимодействия представлена на рисунке 3.

Финансовая составляющая деятельности агротехнопарка заключается в формировании его фонда, включающего членские взносы, средства государственной поддержки, доходы от оказания образовательных и консультационных услуг, внедрения инноваций, часть выручки от реализации продукции экспериментального производства. При получении положительных результатов руководители и специалисты сельскохозяйственных организаций будут премированы из фонда агротехнопарка. Из него же будут возмещаться убытки аграрных организаций, возникшие в результате внедрения инноваций, при условии соблюдения ими технологической дисциплины. Данные меры будут содействовать стимулированию руководителей и специалистов сельскохозяйственных организаций, а также снижать риски инновационной деятельности.

Освоенные технические средства, показавшие свою эффективность, могут быть реализованы аграрным товаропроизводителям со средними показателями результативности производственно-хозяйственной деятельности. При этом амортизацию технических средств в агротехнопарках предлагается начислять ускоренными методами. Это позволит в первые годы эксплуатации списать значительную часть стоимости и реализовывать основные средства менее эффективным сельскохозяйственным организациям по более низкой цене. Также агротехнопарки должны иметь возможность использовать в производственном процессе и реализовывать другим аграрным товаропроизводителям семена высших репродукций, племенной скот и т. п. Агротехнопарки будут оказывать помощь сельскохозяйственным производителям в выборе прогрессивных технологий, сортов сельскохозяйственных культур, племенных животных, удобрений и средств защиты растений. 


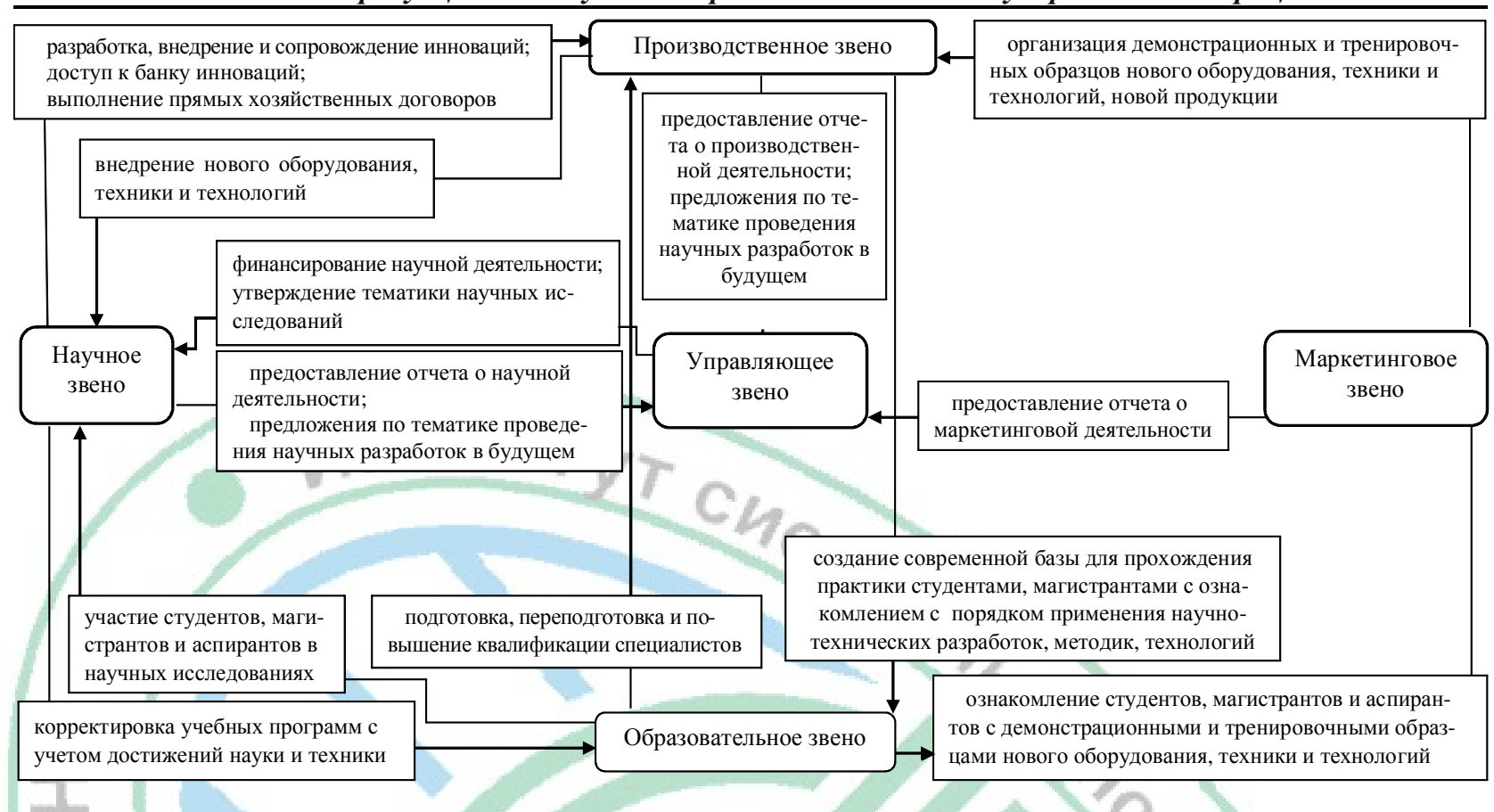

Рис. 3. Модель взаимодействия субъектов агротехнопарка

Примечание. Рисунок составлен автором на основании собственных исследований.

Продвижению инновационных разработок также должна способствовать разветвленная сеть информационно-консультационных центров, входящих в единую информационно-консультационную службу сельского хозяйства, состоящую из трех уровней (районный, областной и республиканский). В качестве субъектов районного уровня должны выступать районные управления по сельскому хозяйству и продовольствию, профессионально-технические учреждения образования аграрного профиля; областного - областные комитеты по сельскому хозяйству и продовольствию, высшие учреждения образования аграрного профиля; республиканского - Министерство сельского хозяйства и продовольствия, научно-исследовательские институты и научнопрактические центры.

Целью сельскохозяйственной информационно-консультационной системы является расширение доступа аграрных товаропроизводителей к информации, касающейся современных достижений науки и техники, инновационных методов производства для повышения эффективности аграрного производства и качества жизни сельского населения.

Создание описанных субъектов планируется на базе различных учреждений и организаций, в перечне функций большинства из них уже присутствует содействие инновационному развитию аграрной отрасли. Однако организация агротехнопарков и информационно-консультационных центров позволит конкретизировать функции участников инновационного процесса, а также оказывать целенаправленную государственную поддержку внедрению инноваций. Данные меры относятся к «зеленой корзине», а следовательно, объем их поддержки не ограничивается требованиями ВТО.

Также в качестве основных направлений совершенствования процесса формирования и развития материально-технической базы сельского хозяйства нами видится: внедрение механизма проектного финансирования, совершенствование амортизационной политики сельскохозяйственных организаций, развитие вторичного рынка технических ресурсов.

Наиболее емким, охватывающим основные особенности проектного финансирования, считаем определение, предложенное В. О. Титовым, который под ним понимает финансовую мультиинструментальную модель с совокупностью инвестиций и долговых кредитных ресурсов специально созданной проектной компании для реализации долгосрочного капиталоемкого высокорискованного инвестиционного проекта, будущие денежные потоки которого являются основным источником возврата заемных средств и выплаты доходов инвесторам и спонсорам, а дополнительные источники возврата - созданные активы в процессе реализации проекта [1]. Данное определение отражает три специфические особенности проектного финансирования: создание проектной компании; возврат привлеченных средств из дохода, генерируемого создаваемым объекTом; одновременное использование нескольких финансовых инструментов, в том числе сочетание долгового и долевого финансирования. На начальной стадии финансирования практически отсутствуют активы для обеспечения возврата занимаемых ресурсов, далее, по мере реализации проекта, создаваемые (приобретаемые) активы могут начинать выступать в качестве залога.

В результате проведенного анализа установлено, что в проектное финансирование могут быть вовлечены основные, привлеченные участники и прочие партнеры. Первая группа включает участников, вкладывающих средства и принимающих инвестиции; вторая субъекты, деятельность которых направлена на эффективную реализацию и обслуживание проекта; третья - 
участники различного профиля, занимающиеся решением широкого спектра вопросов, касающихся хода реализации проекта.

Отношения, возникающие при проектном финансировании, базируются на следующих принципах: платность; срочность; возвратность; обеспеченность (через активы проекта, страхование рисков, их распределение между участниками); целевой характер использования средств; дифференцированный подход со стороны кредитных организаций к инвестиционным проектам; интегрированность (с помощью создания проектной компании) [2]. Таким образом, перечень принципов проектного финансирования значительно шире, чем при кредитовании, ввиду его большей масштабности.

Реализация проекта с помощью проектного финансирования не предусматривает реинвестирования полученного дохода, так как генерируемые средства будут использоваться для возмещения привлеченных ресурсов. Поскольку в данном механизме кредиторы предоставляют ресурсы заемщику (проектной компании) без кредитной истории, реализующему проект с высокой долей заемных ресурсов и существенными обязательствами по уплате процентов по кредиту, то необходимо предусмотреть твердые гарантии выполнения контрактных обязательств по распределению генерируемого проектом денежного потока.

Механизм распределения рисков и дохода устанавливается посредством заключения между проектной компанией и участниками проекта договоров, предусматривающих закрепление рисков и вознаграждения за них за сторонами, способными наиболее успешно управлять ими (рис. 4). Также механизм проектного финансирования предусматривает предоставление гарантий проектной компании участниками инвестиционной деятельности.

В аграрной отрасли с помощью проектного финансирования могут осуществляться проекты, предусматривающие получение положительного эффекта, совместно несколькими аграрными товаропроизводителями, к примеру, строительство собственного цеха по переработке сельскохозяйственной продукции или производству кормов с использованием высокоэффективных инновационных технологий. Дополнительным преимуществом использования проектного финансирования при строительстве таких крупных объектов является возможность привлечения сырья иных товаропроизводителей (участников проекта) для полной загрузки возводимых мощностей или совместное использование готовой продукции. Также с помощью проектного финансирования могут быть объединены ресурсы сельскохозяйственных и перерабатывающих организаций. В качестве цели их сотрудничества может выступать увеличение объемов производства сельскохозяйственной продукции более высокого качества, необходимой переработчику.

Совершенствование амортизационной политики следует проводить с целью создания привлекательных условий для инвестирования развития материально-технической базы, основываясь на следующих принципах: определение оптимального срока полезного использования активов; выбор способов амортизации в зависимости от стратегии развития организации; взаимосвязь стоимости основного капитала и степени его изношенности; возмещение затрат инвестору; учет влияния научно-технического прогресса на воспроизводство долгосрочного капитала; восстановление структуры финансовых балансов в условиях инфляции $[5,6]$.

Считаем, что в амортизационной политике сельскохозяйственных организаций нельзя устанавливать требования обязательного формирования амортизационного фонда. Установление принципа строгого использования амортизационных отчислений на воспроизводство основных средств будет противоречить законодательству. Однако в акционерных обществах (ввиду специфики формы собственности) может быть организован контроль за целевым использованием амортизационных

\begin{tabular}{|c|c|c|}
\hline Участник & Форма распределения рисков & Форма гарантии \\
\hline$\sqrt{7}$ & 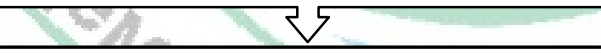 & 10 \\
\hline Государство & $\begin{array}{l}\text { долгосрочные договоры на поставку сырья, } \\
\text { приобретение продукции; постоянство за- } \\
\text { конодательной базы }\end{array}$ & $\begin{array}{l}\text { погашение кредита; выкуп активов про- } \\
\text { екта; фиксирование цен; хеджирование } \\
\text { валютных рисков }\end{array}$ \\
\hline Банки & $\begin{array}{l}\text { фиксация процентов по кредиту; участие } \\
\text { банка в управлении проектом }\end{array}$ & $\begin{array}{l}\text { договоры управления, поставки или } \\
\text { аванса }\end{array}$ \\
\hline Спонсоры & $\begin{array}{l}\text { регресс на имущество; использование «эс- } \\
\text { кроу-счетов»; контракты на управление с } \\
\text { инженерными фирмами }\end{array}$ & $\begin{array}{l}\text { покрытие или возмещение расходов при } \\
\text { недостаточности потоков для обслужи- } \\
\text { вания долга; покрытие дефицитов }\end{array}$ \\
\hline $\begin{array}{c}\text { Генеральный } \\
\text { подрядчик }\end{array}$ & $\begin{array}{l}\text { контракты на строительство «под ключ»; } \\
\text { установление фиксированной стоимости } \\
\text { строительства; осуществление строитель- } \\
\text { ства в оговоренный срок }\end{array}$ & $\begin{array}{l}\text { возмещение перерасходов в ходе строи- } \\
\text { тельства }\end{array}$ \\
\hline $\begin{array}{l}\text { Страховые } \\
\text { компании }\end{array}$ & страхование рисков & $\begin{array}{l}\text { успешное завершение строительства, } \\
\text { исполнение всех обязательств }\end{array}$ \\
\hline
\end{tabular}

Рис. 4. Формы распределения рисков и предоставления гарантий в проектном финансировании 
отчислений со стороны акционеров при принятии ими соответствующего решения. Целевой характер использования амортизационных отчислений следует рассматривать в рамках осуществления инвестиционной деятельности в текущем периоде.

При совершенствовании амортизационной политики особое внимание должно уделяться адекватности проведения переоценки основных средств, то есть соответствию переоцененной их стоимости реальной ситуации. Ведь недооценка основных средств приводит к занижению реальной их стоимости, в результате чего невозможно осуществить полный возврат ресурсов, вложенных в основной капитал. Адекватная переоценка основных средств укрепит финансовое состояние организаций через рост размера собственного капитала организации, который будет способствовать получению дополнительных кредитов благодаря увеличению залоговой стоимости имущества. Для совершенствования процесса переоценки основных средств предлагается ежегодно издавать отраслевой справочник, содержащий актуальные рыночные цены на машины, оборудование и транспортные средства, используемые в аграрном секторе экономики.

Особое внимание при совершенствовании процесса формирования и развития материально-технической базы сельского хозяйства должно уделяться созданию полноценного рынка вторичных технических ресурсов. В результате проведенных исследований нами предложена модель функционирования данного рынка (рис. 5).

Для рынка вторичных технических ресурсов в Республике Беларусь более подходящей считаем трехуровневую схему, в которой аграрные товаропроизводители будут играть различные роли в зависимости от финансового состояния. Среди способов реализации Цель: совершенствование процесса формирования материально-технической базы
сельского хозяйства с помощью создания условий для осуществления взаимовы-
годных сделок участниками рынка

| Субъекты: сельскохозяйственные и агросервисные организации, крестьянскоI фермерские хозяйства $(К(\Phi) Х)$, производители и дилеры сельскохозяйственных машин и оборудования, транспортных средств

| Объекты: подержанные и восстановленные машины и оборудование, транспорт| ные средства, запасные части к ним, услуги по восстановлению технических ресурсов и запасных частей

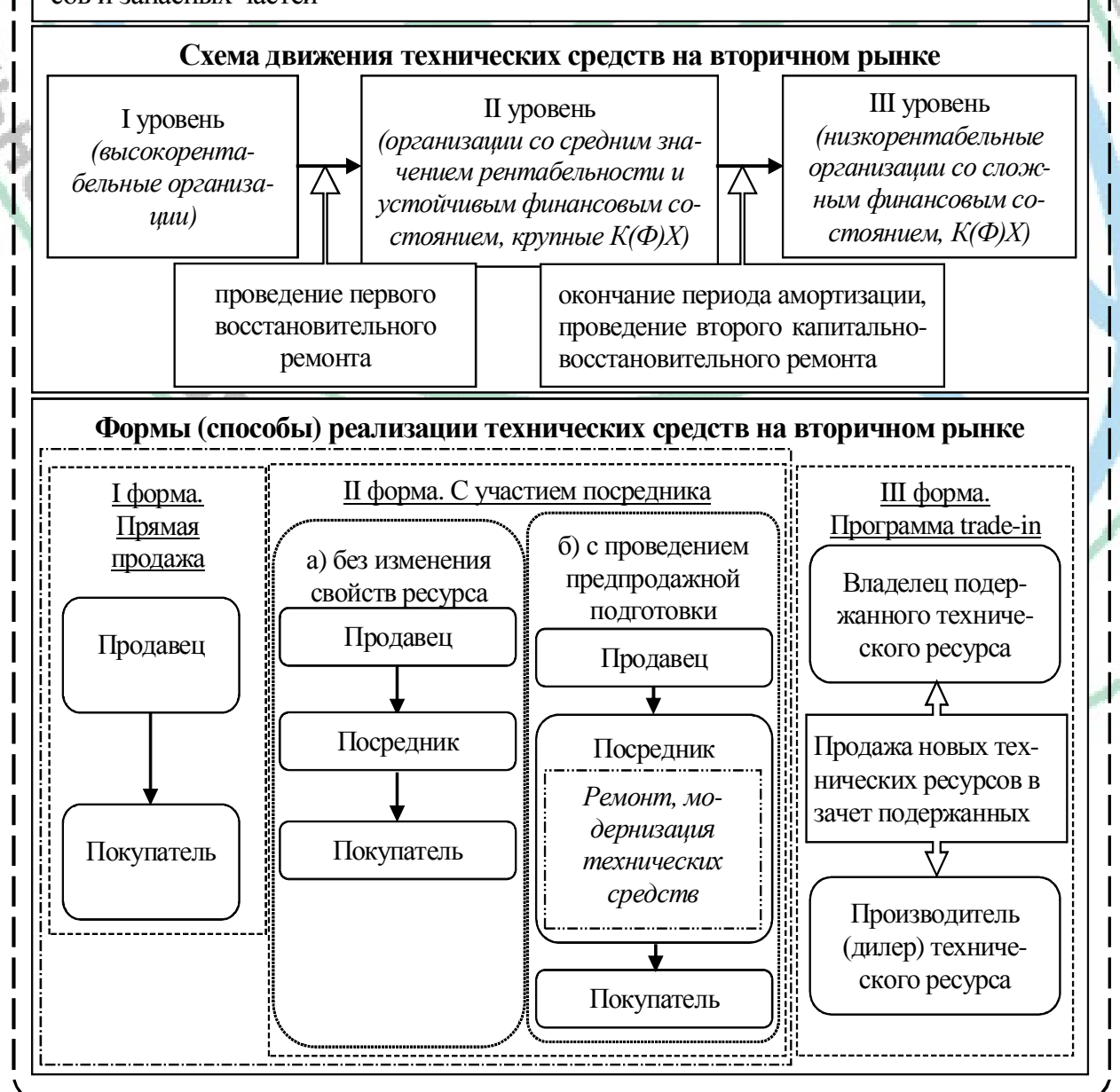

Рис. 5. Модель функционирования вторичного рынка технических ресурсов в аграрной сфере Примечание. Рисунок составлен автором на основании собственных исследований. 
технических ресурсов на вторичном рынке выделяют прямую продажу без посредников и продажу через посредника. Второй способ может иметь два варианта: посредник перепродает технические ресурсы без изменения их свойств; посредник производит предпродажный ремонт или модернизацию технических средств, повышая качественные характеристики. Последний вариант является более приемлемым. Необходимость включения посредников в процесс обосновывается отсутствием у большинства аграрных товаропроизводителей технической, а зачастую и финансовой возможности осуществления полноценного восстановления технических ресурсов. В данной схеме посредник продает готовое к использованию техническое средство, по характеристикам соответствующее новому.

Для развития вторичного рынка технических ресурсов также необходимо повысить доверие к восстановленной технике, главным образом этого можно достичь через повышение качества технического сервиса. Кроме того, организации по восстановлению могут предоставлять гарантии на технические средства или на определенные восстановленные узлы и агрегаты.

Таким образом, по результатам исследования разработаны предложения, способствующие более эффективному развитию материально-технической базы в соответствии с определенными принципами. Так, приведенные алгоритм определения приоритетных направлений инвестирования и методика оценки инвестиционно-инновационного потенциала способствуют определению направлений развития материально-технической базы с учетом имеющихся ресурсов и эффективности их использования. Организационно-экономическая модель формирования и развития материально-технической базы на инновационной основе направлена на сокращение разрыва между наукой и производством благодаря развитию инновационной инфраструктуры, что приведет к более широкому использованию эффективных материально-технических ресурсов, а также распространению информации о новых технологиях. Предложенные направления совершенствования процесса формирования и развития материально-технической базы сельского хозяйства способствуют реализации инвестиционно-инновационных проектов в аграрном секторе экономики и повышению эффективности использования имеющихся ресурсов.

\section{Список использованных источников}

1. Титов, В. О. Проектное финансирование инновационных инвестиционных проектов : автореф. дис. ... канд. экон. наук : 08.00.10 / В. О. Титов ; Санкт-Петербургский гос. Ун-т. - СПб., 2014. - 23 с.

2. Абишева, О. Проектное финансирование в современных условиях: задачи, возможности и характерные особенности / О. Абишева // Статистика, учет и аудит. - 2015. - № 1 (56). - С. 54-59.

3. Смирнов, А. Л. Проектное финансирование: инструменты и технологии / А. Л. Смирнов. - М. : МАКС Пресс, 2013. - 457 с.

4. Филиппова, Л. Е. Проектное финансирование: особенности организации и перспективы развития в Республике Беларусь / Л. Е. Филиппова // Белорус. экон. журн. - 2018. - № 4. - С. 148-159.

5. Сысоев, А. В. Амортизационная политика как фактор инвестиционного развития экономики / А. В. СЫсоев // Проблемы прогнозирования. - 2006. - № 1. С. $61-70$.

6. Туякова, 3. С. Амортизационная политика как элемент стратегии развития промышленных предприятий / 3. С. Туякова // Вестн. Оренбургского гос. ун-та. 2012. - № 1. - C. 131-135.

Материал поступил 14.10.2020 2.

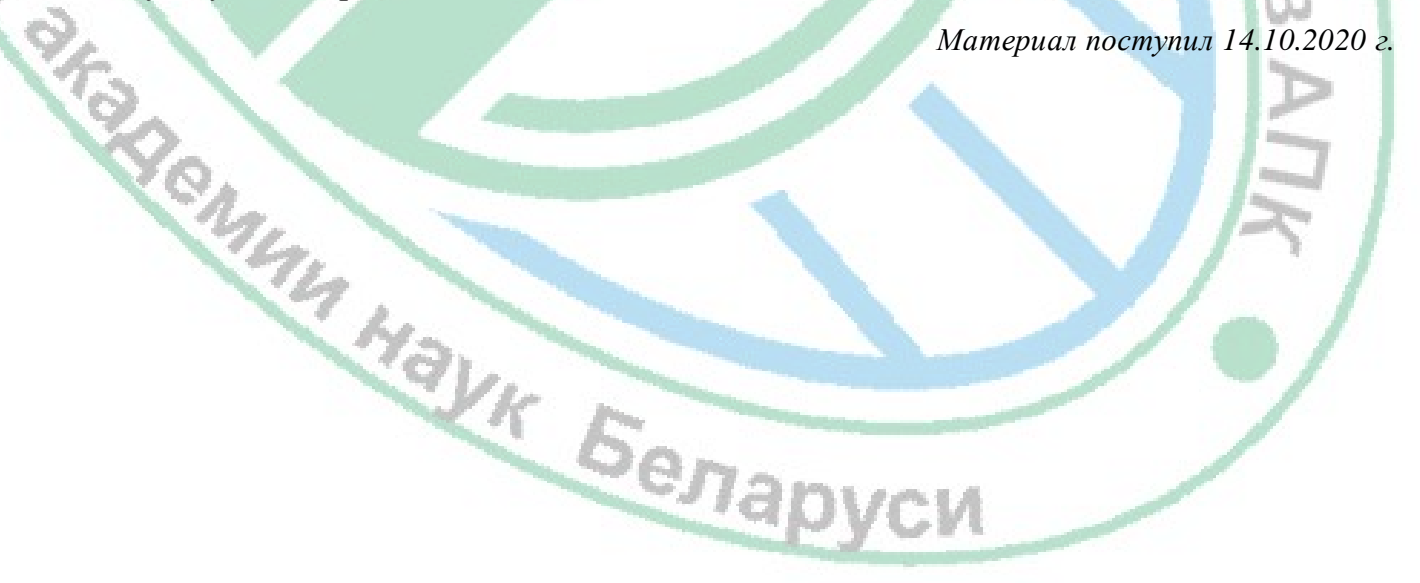

